Article

\title{
Viability of Various Sources to Ignite A2L Refrigerants
}

\author{
Dennis K. Kim and Peter B. Sunderland *(D) \\ Department of Fire Protection Engineering, University of Maryland, College Park, MD 20742, USA; \\ dkim1215@umd.edu \\ * Correspondence: pbs@umd.edu; Tel.: +1-301-405-3095
}

check for updates

Citation: Kim, D.K.; Sunderland, P.B. Viability of Various Sources to Ignite A2L Refrigerants. Energies 2021, 14, 121. https://doi.org/ 10.3390/en14010121

Received: 22 November 2020 Accepted: 23 December 2020 Published: 28 December 2020

Publisher's Note: MDPI stays neutral with regard to jurisdictional claims in published maps and institutional affiliations.

Copyright: () 2020 by the authors. Licensee MDPI, Basel, Switzerland. This article is an open access article distributed under the terms and conditions of the Creative Commons Attribution (CC BY) license (https: / / creativecommons.org/ licenses/by/4.0/).

\begin{abstract}
Environmental considerations are motivating the adoption of low global warming potential refrigerants. Most of these are mildly flammable, i.e., A2L. Their susceptibility to ignition from various ignition sources is poorly understood, particularly for the stoichiometric and quiescent mixtures that are emphasized here. The viability of fifteen residential ignition sources to ignite four A2L refrigerants is considered. Tests are performed in a windowed chamber with a volume of $26 \mathrm{~L}$. The refrigerants are R-32 (difluoromethane); R-452B (67\% R-32, 26\% R-1234yf, and 7\% pentafluoroethane); R-1234yf (2,3,3,3-tetrafluoropropene); and R-1234ze (1,3,3,3-tetrafluoropropene). Two types of ignition sources are confirmed here to be viable: a resistively heated wire at $740{ }^{\circ} \mathrm{C}$ and open flames. When the refrigerant concentration was increased slowly, candle flames and butane flames extinguished before initiating any large deflagrations. Eleven other sources were not viable: a smoldering cigarette, a butane lighter, friction sparks, a plug and receptacle, a light switch, a hand mixer, a cordless drill, a bread toaster, a hair dryer, a hot plate, and a space heater. The difficulty to ignite these refrigerants in air is attributed to their long quenching distances (up to $25 \mathrm{~mm}$ ). Under some conditions the refrigerants were observed to act as flame suppressants.
\end{abstract}

Keywords: combustion; explosion; fire; flame; flammability; halocarbons

\section{Introduction}

Improved sustainability of refrigeration systems will require low global warming potential (GWP) refrigerants. These are generally hydrofluorocarbons or hydrofluoroolefins, for which the same chemistry that causes their rapid destruction in the atmosphere also renders them mildly flammable in air. This mild flammability, classified as A2L, has motivated extensive research [1-5].

The environmental risks of conventional refrigerants must be weighed against the fire hazards of A2L refrigerants. There have been limited risk assessments for A2L refrigerants [6-11], but improving these will require an improved understanding of the viability of ignition sources to ignite these refrigerants. As of December 2019, there had been no serious accidents in the 68 million units charged with A2L refrigerants [12], but this could change as these new systems age.

The A2L classification indicates a lower flammability limit (LFL) above 3.5\% by volume, a lower heating value enthalpy of combustion (LHV) below $19 \mathrm{~kJ} / \mathrm{g}$, and a laminar flame speed $\left(S_{L}\right)$ below $10 \mathrm{~cm} / \mathrm{s}$ [13]. Mildly flammable refrigerants are well understood in terms of their LFL, LHV, and $S_{L}$. Less is known about their ignitibility by potential ignition sources such as hot surfaces, open flames, smoldering materials, electric arcs, and residential appliances.

Table 1 shows several combustion properties of four common A2L refrigerants in air. These are LFL and upper flammability limit (UFL), dry and moist stoichiometric mole fractions, LHV, $S_{L}$, flame quenching distance $\left(L_{q}\right)$, autoignition temperature (AIT), and minimum ignition energy (MIE). 
Table 1. Selected combustion properties in air of four A2L refrigerants and R-290.

\begin{tabular}{|c|c|c|c|c|c|c|c|c|c|}
\hline \multirow{2}{*}{$\begin{array}{c}\text { Refrig- } \\
\text { erant }\end{array}$} & \multirow{2}{*}{ Form. } & \multicolumn{3}{|c|}{ Mole Fraction, \% } & \multirow{2}{*}{$\begin{array}{c}\text { LHV [14], } \\
\quad k J / g\end{array}$} & \multirow[t]{2}{*}{$\mathrm{S}_{\mathrm{L}},(\mathrm{cm} / \mathrm{s})$} & \multirow[t]{2}{*}{$L_{q}[15], \mathbf{m m}$} & \multirow[t]{2}{*}{$\mathrm{AIT},{ }^{\circ} \mathrm{C}$} & \multirow[t]{2}{*}{ MIE, mJ } \\
\hline & & LFL-UFL & $\begin{array}{c}\text { Dry Stoic. } \\
{[16]}\end{array}$ & $\begin{array}{c}\text { Moist } \\
\text { Stoic. [16] }\end{array}$ & & & & & \\
\hline $\mathrm{R}-32$ & $\mathrm{CH}_{2} \mathrm{~F}_{2}$ & $14.4-29.3$ [17] & 17.4 & - & 10.3 & 6.7 [14] & 7.55 & 764 [10] & $65[18]$ \\
\hline $\mathrm{R}-452 \mathrm{~B}$ & - & $11.9-24$ [11] & 14.7 & 14.3 & - & - & - & - & - \\
\hline R-1234yf & $\mathrm{C}_{3} \mathrm{H}_{2} \mathrm{~F}_{4}$ & $6.2-12.3[17]$ & 7.8 & 7.2 & 9.3 & 2.7 [19] & 24.8 & 405 [20] & 7500 [18] \\
\hline R-1234ze & $\mathrm{C}_{3} \mathrm{H}_{2} \mathrm{~F}_{4}$ & $7-9.5$ [17] & 7.8 & 7.2 & - & $2.1[19]$ & - & 368 [21] & $63,000[17]$ \\
\hline R-290 & $\mathrm{C}_{3} \mathrm{H}_{8}$ & $2.2-10[17]$ & 4 & - & 46.4 & 38.7 [14] & 1.75 & 504 [6] & 0.25 [17] \\
\hline
\end{tabular}

Also shown in Table 1 are the corresponding properties of R-290 (n-propane). Compared to the halocarbons, R-290 has the lowest LFL, stoichiometric mole fraction, $L_{q}$, and MIE, and the highest UFL/LFL ratio, LHV, and $S_{L}$. The only property here for which R-290 is not an outlier is AIT.

Several conditions are necessary to ignite a gas mixture: it must be between the LFL and UFL; the ignition source must exceed the MIE and/or the AIT; and the flame must have a path that is free of cool surfaces within a distance of $0.5 L_{q}$. These conditions are necessary but not sufficient. For example, they do not consider fluid motion or the duration of the ignition source. Therefore, the most conclusive way to assess the viability of an ignition source is to perform tests.

Potential ignition sources for A2L refrigerants were identified and tested by many past studies $[6,8,9,18,21-24]$. These emphasized refrigerant jets in air. Open flames can ignite jets of A2L refrigerants $[6,8,18,24-26]$, but this is not universally observed $[1,21]$ and it has not been tested when the refrigerant concentration increases slowly. Hot surfaces can ignite A2L refrigerants $[10,18,20,21,24,27,28]$, but again the results are found to vary with the conditions and, often, to be stochastic.

Unfortunately, past studies did not consider a sufficiently wide array of ignition sources or refrigerants. Furthermore, jets and slowly increasing refrigerant concentrations are less likely to ignite than quiescent premixtures, which have only been tested with strong electric arcs and hot wires [3,14,29-32].

Thus motivated, the objective of this study is to observe the viability of various potential residential ignition sources to ignite $\mathrm{A} 2 \mathrm{~L}$ refrigerants in air. The refrigerants considered are R-32 (difluoromethane), R-452B (67\% R-32, 26\% R-1234yf, and 7\% pentafluoroethane), R-1234yf (2,3,3,3-tetrafluoropropene), and R-1234ze (1,3,3,3-tetrafluoropropene). For weak ignition sources, only stoichiometric mixtures are considered. For strong sources, leaner but still flammable mixtures are considered owing to safety considerations.

Several factors are not considered in these tests. For example, a refrigerant leak can be accompanied with a release of flammable oil mist $[10,20,25]$, which increases flammability, or flashing refrigerant, which decreases flammability. Turbulence generally decreases the ignition propensity, but can increase the rate of transport of reactants toward the ignition source. Humidity is not expected to affect R-32 ignition, but it can for A2L refrigerants with F:H atomic ratios above unity.

\section{Experimental Methods}

The apparatus is shown in Figure 1. The chamber is cubical with an internal dimension of $29.7 \mathrm{~cm}$ and a volume of $26 \mathrm{~L}$. Three of the chamber's sides and its bottom are made of $3 \mathrm{~mm}$ thick stainless steel. The front is $10 \mathrm{~mm}$ thick transparent poly(methyl methacrylate) for optical access. All tests were recorded with a video camera (Casio Exilim EX-FH100) at $30 \mathrm{frames} / \mathrm{s}$. For several potential ignition sources, temperatures were measured with bare-wire type $\mathrm{K}$ thermocouples with wire diameters of $125 \mu \mathrm{m}$. The mixing fan had a flowrate of $3 \mathrm{~m}^{3} / \mathrm{min}$. 


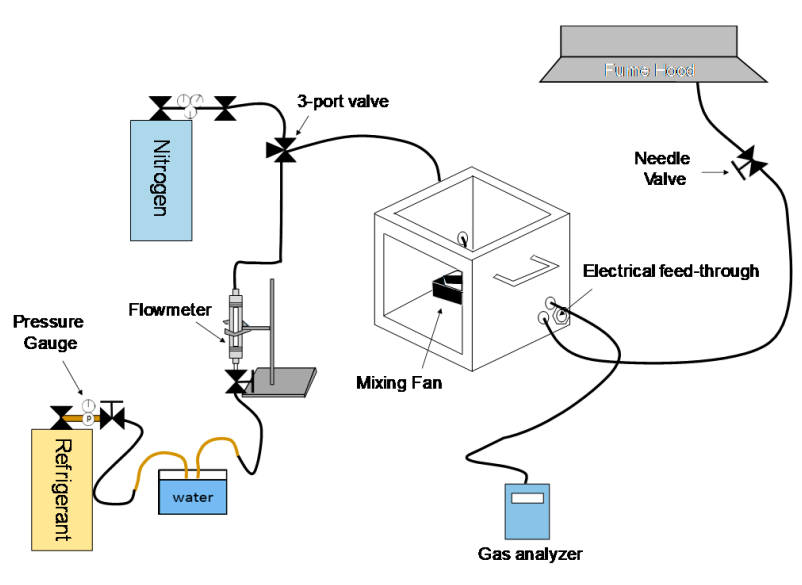

(a)

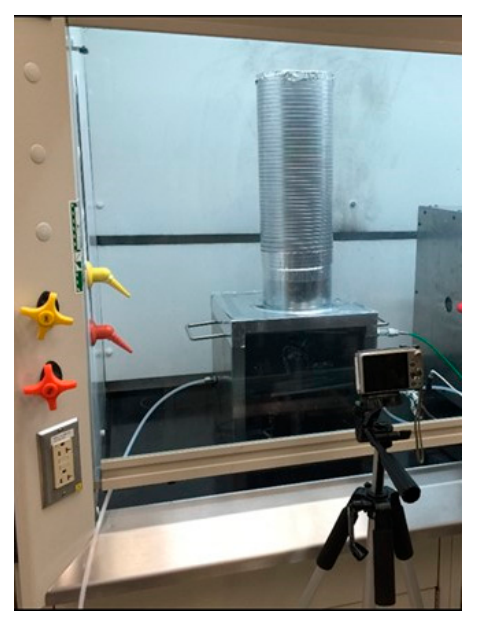

(b)

Figure 1. (a) Experimental setup; (b) Image of the chamber and its chimney.

Before each test the chamber was flushed with air (at $22{ }^{\circ} \mathrm{C}, 1.01 \mathrm{bar}$, and a relative humidity of $40 \%$ ). The chamber top was sealed with aluminum foil, tape, and (for most tests) a chimney, as shown in Figure 1b. When so sealed the chamber was airtight. The foil leading to the chimney was thinner, such that it ruptured during tests with sufficient heat release rates.

The monomer refrigerants were extracted from their containers in the vapor phase, but R-452B, a non-azeotropic blend, was extracted in the liquid phase and flashed upon leaving the pressure regulator. The refrigerants were supplied to the chamber via a pressure regulator, a copper tube in a water bath at $22{ }^{\circ} \mathrm{C}$ to facilitate flow measurement, and a rotameter flowmeter.

For premixed tests the vent tube connecting the chamber to the exhaust was open and the fan was on while refrigerant was flowed at 1 LPM into the chamber. Assuming the chamber contents were fully mixed, the refrigerant mole fraction in the chamber, $X$, was

$$
\mathrm{d} X / \mathrm{d} t=(1-X) Q / V
$$

where $Q$ is the refrigerant volumetric flow rate, $t$ is time, and $V$ is the chamber volume. When the desired concentration was established (typically after $5 \mathrm{~min}$ ) the flow was terminated and the vent tube was closed. The fan remained enabled for $1 \mathrm{~min}$, during which it delivered 54 times the chamber volume. The fan was then turned off and a thermalconductivity gas analyzer (New Cosmos XP-3140) confirmed the refrigerant concentration. The gas analyzer was calibrated for each refrigerant using partial pressures in a $12 \mathrm{~L}$ vessel. After a hold of 2 min to ensure quiescent conditions, the ignition test was performed.

For jet tests, the ignition source was energized and then the refrigerant was introduced at 1 LPM with the fan off.

In the presence of flames or sufficient heat, these refrigerants produce toxic HF and $\mathrm{COF}_{2}$. To prevent their release into the laboratory the chamber was installed inside a sash fume hood. After each test, the chamber was flushed with nitrogen and air for at least 10 min with the fan running.

Ignition limits can be difficult to measure repeatably, as they can vary with small changes in the test conditions $[3,7,19,29,30,33-37]$. Fortunately, the tests reported here are not believed to be close to ignition limits. Nevertheless, the test conditions were carefully controlled and sufficient repeat tests were performed. 


\section{Results}

\subsection{Premixed Tests with Resistively Heated Wires}

Tests were performed with resistively heated $\mathrm{Ni}-\mathrm{Cr}$ wires located $7 \mathrm{~cm}$ above the chamber floor. Each wire had a diameter of $0.32 \mathrm{~mm}$, a length of $16 \mathrm{~cm}$, and 10 coils formed by wrapping the wire around a $4 \mathrm{~mm}$ tube that was then removed. The relationship between wire excitation and temperature was measured in air with a thermocouple. For a slowly increasing excitation, the wires ruptured at an excitation of 12 VAC and a temperature of $1140{ }^{\circ} \mathrm{C}$.

The chamber was filled with the refrigerant/air mixtures shown in Table 2. The chamber contents were well mixed and quiescent. The wire was then energized with a variable transformer whose output was increased at a rate of $0.5 \mathrm{~V} / \mathrm{s}$.

Table 2. Hot wire tests that resulted in ignition.

\begin{tabular}{|c|c|c|c|c|c|}
\hline Test & Refrigerant & $X, \%$ & Mixture & $V$, VAC & Wire $T,{ }^{\circ} \mathrm{C}$ \\
\hline 1 & \multirow{3}{*}{$\mathrm{R}-32$} & 13 & Lean & 8 & 788 \\
\hline 2 & & 17 & Lean & 7.5 & 744 \\
\hline 3 & & 17.4 & Stoichiometric & 8.9 & 863 \\
\hline 4 & \multirow{2}{*}{ R-452B } & 10 & Lean & 8 & 788 \\
\hline 5 & & 14.7 & Stoichiometric & 9.4 & 911 \\
\hline 6 & R-1234yf & 7.8 & Stoichiometric & 9.5 & 921 \\
\hline 7 & \multirow{2}{*}{ R-1234ze } & 6.5 & Lean & 8 & 788 \\
\hline 8 & & 7.8 & Stoichiometric & 9.5 & 921 \\
\hline
\end{tabular}

Table 2 shows the excitation, $V$, and corresponding wire temperature at which ignition was observed. (Tests with $7.8-10 \%$ R-32 were also performed but are not shown in Table 2 because no combustion was detected before the wire ruptured.) These mixtures are generally between the LFL and UFL of Table 1, but tests 1 and 4 are slightly below the LFL, which is defined based on a weaker ignition source and a larger flame threshold. For each test in Table 2, the flames remained anchored to the hot wire, burned for about $3 \mathrm{~s}$, and then self-extinguished.

Figure 2 shows a representative flame image (tests 3, 5, 6, and 8) for each refrigerant. The R-32 flames propagated upward and outward from the hot wire, reached the top of the chamber, and then propagated downward until reaching the chamber floor. The other flames propagated upward to the ceiling, where they spread to the walls but not far downward. The flame surfaces for R-32 were generally smoother and less cellular.
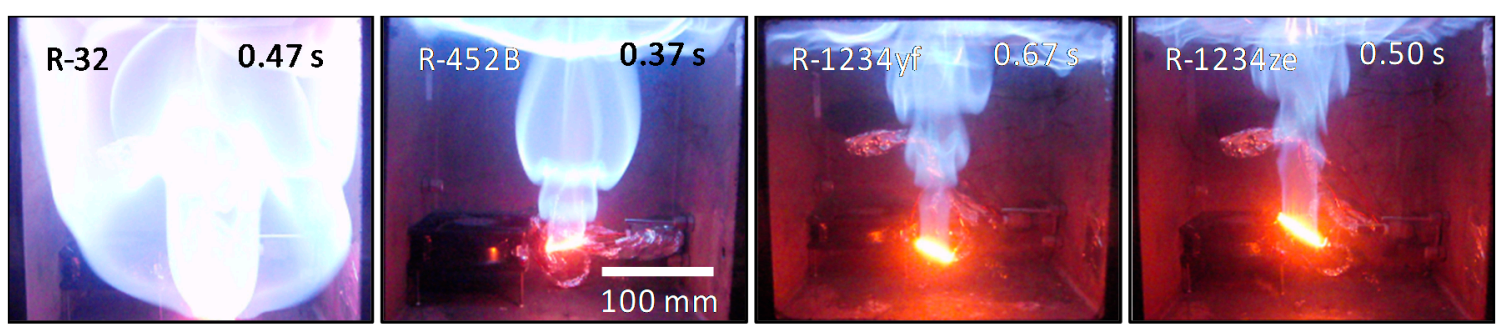

Figure 2. Images of ignition tests of stoichiometric mixtures with resistively heated wires. Images correspond to the largest flame for each test. The times shown are elapsed times after the onset of flaming. A video of these tests is provided in the Supplementary Materials Video S2.

The flames were mostly blue, although yellow emissions, attributed to metals from the wires, were occasionally visible. The R-32 flames were the brightest.

It is clear from these tests that a resistively heated wire at $740{ }^{\circ} \mathrm{C}$ or above can be a viable ignition source for premixtures of these refrigerants. 


\subsection{Premixed Tests with Open Flames}

Open flames were tested in premixtures using safety match heads and butane flames.

The safety matches were $50 \mathrm{~mm}$ long and vertical. Their heads had diameters and lengths of 2 and $3 \mathrm{~mm}$, respectively, and were $10 \mathrm{~cm}$ above the chamber floor. The heads were wrapped with and ignited by $\mathrm{Ni}-\mathrm{Cr}$ wires with diameters and lengths of 0.32 and $10 \mathrm{~mm}$, respectively.

The chamber was filled with the nearly stoichiometric refrigerant/air mixtures shown in Figure 3. The chamber contents were well mixed and quiescent. The wires were energized suddenly at $2 \mathrm{VAC}$, igniting the match heads within $2 \mathrm{~s}$. Tests performed without match heads established that the wires alone were too short and cool to ignite the refrigerant mixtures.
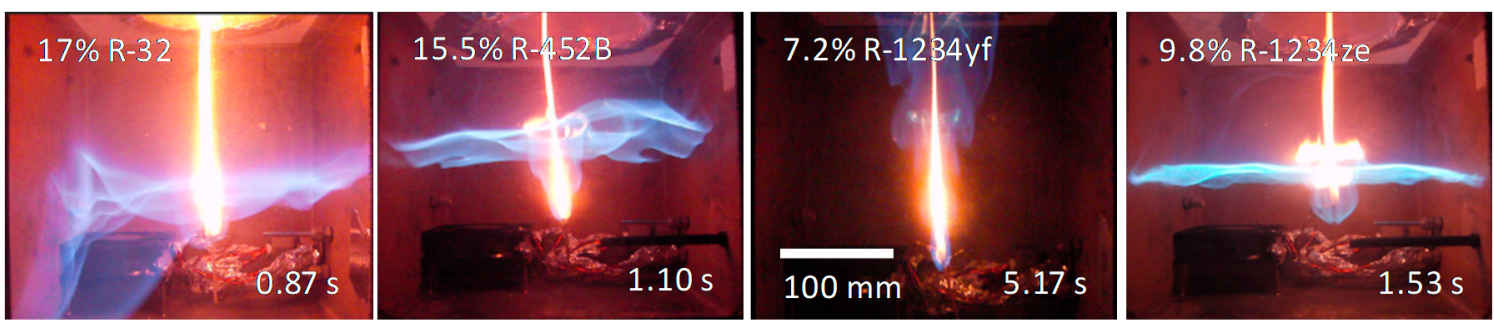

Figure 3. Images from safety match tests corresponding to the largest flame for each test. The times shown are elapsed times after the onset of flaming. A video of these tests is provided in the Supplementary Materials Video S3.

As shown in Figure 3, all four mixtures were ignited by the open flames. The flames burned for about $3 \mathrm{~s}$ and then self-extinguished. In these images the blue regions are the refrigerant flames and the yellow regions are soot from the burning match heads.

The R-32 and R-1234ze flames were similar: blue flames propagated upward and outward from the match heads, reached the top of the chamber, and then propagated downward to the chamber floor. The flame surface for R-32 was smoother and less cellular. For R-452B and R-1234yf the flames propagated upward from the safety match and then downward after reaching the top of the chamber, but never reached the chamber floor.

Premixed tests were also performed with butane flames. For these the quiescent flammable mixtures of Figure 4 were prepared in the chamber. A butane lighter was ignited outside the chamber and then inserted in a $10 \mathrm{~mm}$ hole in the right side of the chamber about $40 \mathrm{~mm}$ above the chamber floor. Deflagrations resulted that lasted about $3 \mathrm{~s}$.
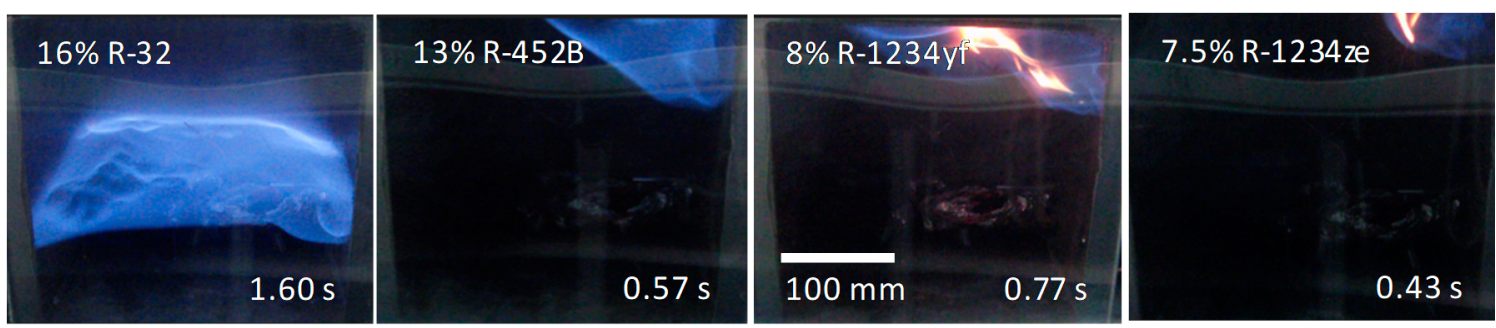

Figure 4. Images from butane flame insertion tests corresponding to the largest flame for each test. The times shown are elapsed times after the onset of flaming. A video of these tests is provided in the Supplementary Materials Video S4.

In every case with flammable mixtures flames propagated in the refrigerants. Only for R-32 did the flame burn upward to the ceiling and then downward to the floor. For the other refrigerants the flames propagated upward to the ceiling, but not downward.

Tests were also performed where the butane flame was introduced into homogeneous mixtures of R-32 below the LFL. The butane flame extinguished quickly, but this did not happen when the chamber was filled with air. As discussed in Section 3.5, this behavior is attributed to the suppressive effects these refrigerants can have for some flames. 
It is clear from these tests that an open flame-either a match head or a lighter-can be a viable ignition source for these refrigerants. This is consistent with past observations of R-32 and R-1234yf [6,18,24,26].

\subsection{Jet Tests with Open Flames}

Open flames were tested with refrigerant jets using candles and butane flames.

For most of the candle tests a lit candle with a flame height of $50 \mathrm{~mm}$ was installed in the center of the chamber with its flame base $50 \mathrm{~mm}$ above the chamber floor. The chamber was quickly sealed, the 1 LPM flow of gaseous refrigerant commenced, and the flaming behavior was observed until all flames were extinguished. The fan was not used, but there was considerable convective mixing owing to the refrigerant jet and the flame buoyancy. For most tests the refrigerant jet was near the floor, but similar results were obtained when it was near the ceiling.

A total of 25 candle tests were performed. Representative images are shown in Figure 5. The flames were initially yellow, but as the tests progressed blue emissions also appeared except for R-452B. The blue emissions, attributed to refrigerant burning, were always limited to the region near the candle axis. The large refrigerant deflagrations observed for premixed tests above were not observed for these jet tests.
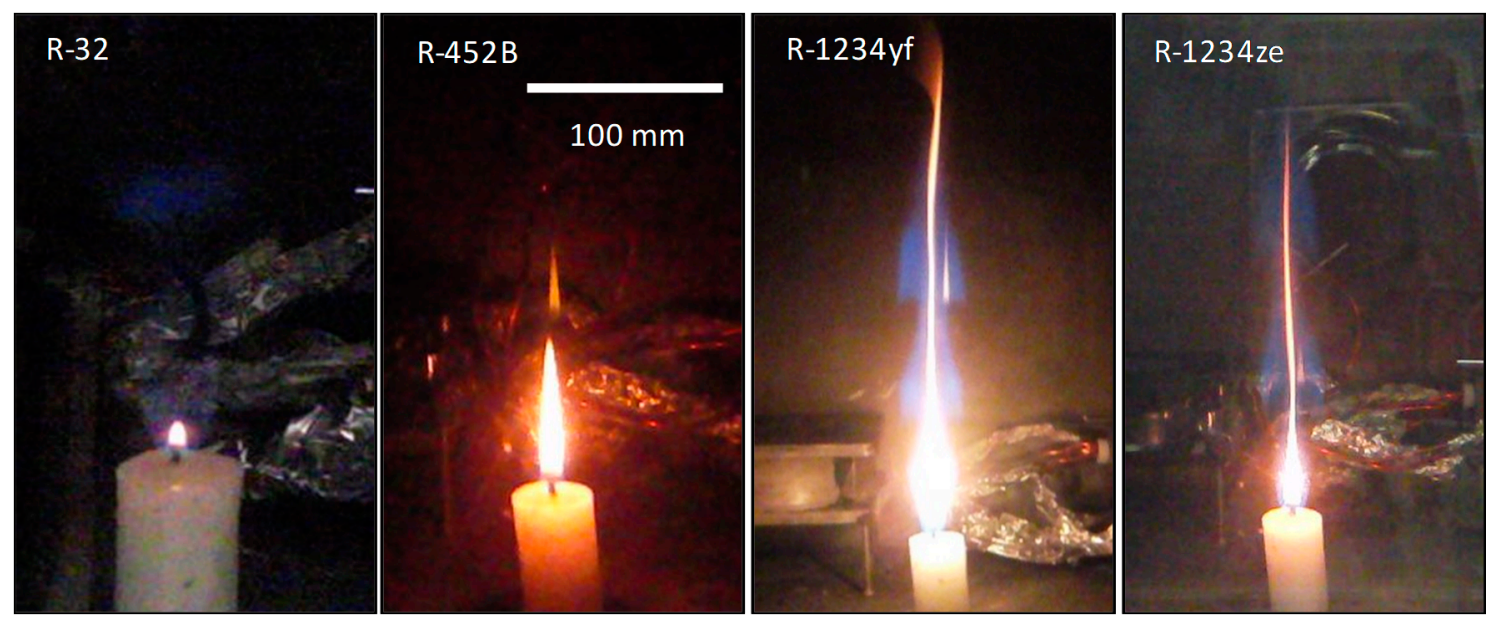

Figure 5. Images from candle tests corresponding to the largest flame for each test. A video of these tests is provided in the Supplementary Materials Video S5.

The yellow and blue flames of Figure 5 shrank until they extinguished after 65-84 s of flow, corresponding to $3-4.7 \%$ refrigerant mole fractions assuming perfect mixing. The 21 other tests extinguished after 60-177 s of refrigerant flow, corresponding to refrigerant mole fractions of $3.5-9.2 \%$.

For several tests the candle was placed near a corner, with similar results. For several others the flame base was at a height of $150 \mathrm{~mm}$, which delayed the extinction times (for a R-32 mean of $140 \mathrm{~s}$ compared to a mean of $80 \mathrm{~s}$ at a height of $50 \mathrm{~mm}$ ).

A jet test was also performed with a butane lighter. The chamber was filled with quiescent air and the top was sealed. The butane flame was ignited and inserted in a $10 \mathrm{~mm}$ hole $40 \mathrm{~mm}$ above the chamber floor. The flow of R-32 was commenced. Yellow and blue flames were observed until they shrank and extinguished after $70 \mathrm{~s}$ and could not be reignited with the lighter's piezoelectric arc ignitor. Assuming well-mixed conditions, the R-32 mole fraction was 3.8\%.

These candle and butane flame extinction events are attributed here to the ability of halocarbons to suppress some flames, see Section 3.5. However, several other factors could have contributed, as discussed next. 
Turbulence from the jets was ruled out as a factor by performing candle tests with air jets far larger than 1 LPM. Although the candles flickered, they did not extinguish. Furthermore, jet turbulence is not evident in the images or video of Figure 5.

Gas stratification is possible in these tests, as the refrigerants have higher molar masses than air. It is possible that the tests involved rich regions near the floor, lean regions near the ceiling, and only a thin layer between the LFL and UFL. The approximate diffusion layer thickness for a planar stratified layer of these refrigerants and air is

$$
L=(D t)^{0.5}
$$

where $D$ is the mass diffusivity of $\mathrm{C}_{3} \mathrm{H}_{2} \mathrm{~F}_{4}$ in air at $298 \mathrm{~K}$, i.e., $8.0 \mathrm{~mm}^{2} / \mathrm{s}$ [38], and $t$ is time. For the present candle extinction times of around $100 \mathrm{~s}$, this thickness is $28 \mathrm{~mm}$, which is not thin relative to the candle flame length. Furthermore, the turbulence in the jets and buoyant flows near the flames serve to decrease any stratification.

Chemical reactions in these jet tests deplete the oxygen available for combustion. Tests with a candle burning in the chamber without any refrigerant found the flame to extinguish after 15 min owing to oxygen starvation. Based on the measured change in candle mass and an assumed wax composition of $\mathrm{C}_{24} \mathrm{H}_{50}$, the final oxygen mole fraction in the chamber is estimated at $17 \%$. This is reasonably close to the limiting oxygen index (LOI) of $14.5 \%$ for heptane [39], which is a good surrogate for candle wax. For tests with candles and refrigerant, the flame sizes can increase, and the mean oxygen consumption rate is estimated conservatively at twice that of a candle in air. The refrigerant mole fraction at the time of extinction for these tests was $9.2 \%$ or less. Therefore, the time at which the LOI was reached in these tests is estimated at:

$$
t=(15 \mathrm{~min}) 0.5(1-0.092)=6.8 \mathrm{~min}
$$

Any test that continues for 6.8 min or longer could be corrupted by effects of oxygen depletion. However, all these flames extinguished within $3 \mathrm{~min}$.

\subsection{Non-Viable Ignition Sources}

As discussed below, quiescent premixed tests with all four refrigerants at stoichiometric conditions were performed with eleven potential ignition sources. None resulted in any visible flames in the refrigerant/air mixtures. Table 3 summarizes these tests, showing the excitation, $V$, the current, $I$, the peak measured temperature, $T$, and the number of trials, $N$, or the test time, $t$, for each refrigerant. Additional details are provided in [16].

\begin{tabular}{|c|c|c|c|c|c|}
\hline Source & $V, \mathrm{VAC}$ & I, Amps & $T,{ }^{\circ} \mathrm{C}$ & $N$ & $t, \mathrm{~s}$ \\
\hline Smoldering cigarette & - & - & 490 & 4 & - \\
\hline Butane lighter & - & - & - & 10 & - \\
\hline Friction sparks & - & - & $3000^{a}$ & - & 60 \\
\hline Plug and receptacle & 120 & 15 & - & 10 & - \\
\hline Light switch & 120 & 15 & - & 20 & - \\
\hline Hand mixer & 120 & 1.7 & - & - & 120 \\
\hline Cordless drill & 18 & 21 & - & - & 120 \\
\hline Bread toaster & 120 & 6 & 500 & - & 120 \\
\hline Hair dryer & 120 & 13 & 200 & - & 60 \\
\hline Hot plate & 120 & 6 & 540 & 1 & - \\
\hline Space heater & 120 & 12 & 100 & 1 & - \\
\hline
\end{tabular}

Table 3. List of non-viable ignition sources. 
Smoldering cigarettes were tested by inserting them after the chamber was filled with refrigerant and air. The ember temperature was similar to the AIT for these refrigerants. In each test the cigarette extinguished within $100 \mathrm{~s}$, which is consistent with past results of R-32 and R-1234yf [18]. Oxygen depletion was ruled out because when the chamber was filled with only air the cigarettes smoldered until the tobacco was depleted after 16 min.

A butane lighter with a piezoelectric arc ignitor was tested with the lighter tip inside the chamber and the trigger outside and activated with a solenoid. The butane flame ignited when the chamber contained $2 \%$ R-32, but not when it contained 3\% or more R-32.

Friction sparks were tested in the chamber using a grinding stone, driven by a cordless drill, in contact with a ferrocerium flint rod. Temperatures of $3000{ }^{\circ} \mathrm{C}$ are typical of such friction sparks. Continuous streaks of friction sparks $3 \mathrm{~cm}$ long were generated.

The plug and receptacle and the single-pull light switch were cycled in the chamber using a solenoid while a load outside the chamber was connected. Continuous electric arcs were visible. For both the hand mixer and the cordless drill with a brushed motor, continuous blue arcs were visible. The two-slice bread toaster had outside dimensions of $15 \times 29 \times 18 \mathrm{~cm}$. The hand-held hair dryer had a blower and a heating element.

The countertop hot plate could not be operated for long periods inside the chamber without damaging the window. Instead it was inverted and heated and then lowered into the chamber by quickly rupturing the aluminum foil. No chimney was used. Similarly, the ceramic tower space heater was too high $(0.58 \mathrm{~m})$ to be sealed in the chamber so it was heated and then lowered into the chamber by quickly rupturing the aluminum foil without the chimney present.

The hair dryer and space heater did not ignite the refrigerants because their peak temperatures were below the mixture AITs. The other sources in Table 3 had sufficiently high temperatures, but did not ignite the refrigerants owing to the large $L_{q}$ of these refrigerants. The AITs were not exceeded beyond distances on the order of $0.5 L_{q}$ from solid surfaces.

\subsection{Halocarbons as Fuels or Suppressants}

As the above tests demonstrate, these halocarbon refrigerants can act either as fuels or suppressants. For mixtures between the LFL and UFL and a strong ignition source, large deflagrations result. On the other hand, slowly increasing refrigerant concentrations suppress candle and butane flames; quiescent homogeneous mixtures well below the LFL suppress butane flames; smoldering cigarettes are suppressed by homogeneous stoichiometric mixtures; and an arc is unable to ignite a butane flame for R-32 mole fractions above $3 \%$. Such evidently conflicting behavior was previously reported for halocarbons by [30], who found that $\mathrm{C}_{6} \mathrm{~F}_{12} \mathrm{O}, \mathrm{C}_{3} \mathrm{H}_{2} \mathrm{~F}_{3} \mathrm{Br}$, and $\mathrm{C}_{2} \mathrm{HF}_{5}$ can either enhance or suppress burning.

\section{Conclusions}

Fifteen potential ignition sources were tested to determine their viability to ignite mixtures of mildly flammable refrigerants and air. The refrigerants were R-32, R-452B, R-1234yf, and R-1234ze. Both quiescent premixed tests and jet tests were performed. The key conclusions are as follows.

1. $\mathrm{NiCr}$ wires heated resistively to $740{ }^{\circ} \mathrm{C}$ and open flames (burning safety matches and butane) are viable ignition sources for quiescent premixtures of refrigerant and air above the LFL. Large deflagrations were observed that propagated up to the ceiling and then down to the floor.

2. When the refrigerant concentration was increased slowly, every candle or butane flame extinguished before initiating any large deflagrations.

3. Eleven other potential residential ignition sources did not produce any flames in quiescent stoichiometric refrigerant/air mixtures. These included a smoldering cigarette, a pizeoelectric butane lighter, electric arcs, motors, and various residential heating elements at $540{ }^{\circ} \mathrm{C}$ and below.

4. Depending on the conditions, these A2L halocarbon refrigerants can act as either fuels or suppressants. They act as fuels for a strong ignition source like a resistively heated 
hot wire or for an open flame suddenly introduced into a flammable mixture. For weaker sources or refrigerant mixtures below the LFL, they act as suppressants.

Supplementary Materials: The following are available online at https:/ /www.mdpi.com/1996-1 073/14/1/121/s1, Videos S2.mp4, S3.mp4, S4.mp4, and S5.mp4 are color videos of the tests of Figures $2-5$, respectively.

Author Contributions: D.K.K. performed the literature review, the tests, and the analyses, and prepared the tables and figures. P.B.S. directed the research and the manuscript preparation. Both authors have read and agreed to the published version of the manuscript.

Funding: This work was funded by AHRI 8017 grant, with Xudong Wang serving as technical contact.

Acknowledgments: Assistance with the experiments was provided by A. Hermman, A. Klieger, M. Kokot, V. Lecoustre, P. Lomax, C. McCoy, and J. Reymann.

Conflicts of Interest: The authors declare no conflict of interest. The funders assisted in the design of the study.

\section{Nomenclature}

$\begin{array}{ll}\text { AIT } & \text { Autoignition temperature } \\ D & \text { Mass diffusivity } \\ I & \text { Current } \\ L & \text { Approximate diffusion layer thickness } \\ \text { LFL } & \text { Lower flammability limit } \\ \text { LHV } & \text { Lower heating value enthalpy of combustion } \\ \text { LOI } & \text { Limiting oxygen index } \\ \text { LPM } & \text { Liter per minute } \\ L_{q} & \text { Quenching distance } \\ \text { MIE } & \text { Minimum ignition energy } \\ N & \text { Number of trials } \\ Q & \text { Refrigerant volumetric flow rate } \\ S_{L} & \text { Laminal flame speed } \\ T & \text { Temperature } \\ t & \text { Time } \\ \text { UFL } & \text { Upper flammability limit } \\ V & \text { Chamber volume; also excitation } \\ X & \text { Refrigerant mole fraction }\end{array}$

\section{References}

1. Davis, S.G.; Pagliaro, J.L.; DeBold, T.F.; van Wingerden, M.; van Wingerden, K. Flammability and explosion characteristics of mildly flammable refrigerants. J. Loss Prev. Proc. Ind. 2017, 49, 662-674. [CrossRef]

2. Kujak, S. Flammability and new refrigerant options. ASHRAE J. 2017, 59, 16-24.

3. Kim, D.K.; Klieger, A.E.; Lomax, P.Q.; McCoy, C.G.; Reymann, J.Y.; Sunderland, P.B. An improved test method for refrigerant flammability limits in a $12 \mathrm{~L}$ vessel. Sci. Tech. Built Environ. 2018, 24, 861-866. [CrossRef]

4. Burrell, R.R.; Pagliaro, J.L.; Linteris, G.T. Effects of stretch and thermal radiation on difluoromethane/air burning velocity measurements in constant volume spherically expanding flames. Proc. Combust. Inst. 2019, 37, 4231-4238. [CrossRef] [PubMed]

5. Pierantozzi, M.; Tomassetti, S.; Nicola, G. Climate change and refrigerants: Thermodynamic properties of low-GWP fluids for domestic applications and binary systems for low-temperature options. Appl. Sci. 2020, 10, 2014. [CrossRef]

6. Goetzler, W.; Bendixen, L.; Bartholomew, P. Risk Assessment of HFC-32 and HFC-32/134a (30/70 wt.\%) in Split System Residential Heat Pumps; Final Report No. DOE/CE/23810-92; ARTI MCLR Project Number 665-52402; Arthur D. Little, Inc.: Cambridge, MA, USA, 1998; 88p.

7. Clodic, D.; Riachi, Y. A method for determining practical flammability risk when using refrigerant blends. HVACER Res. 2009, 15, 819-834.

8. Goetzler, W.; Burgos, J. Study of input parameters for risk assessment of 2L flammable refrigerants in residential air conditioning and commercial refrigeration applications. ASHRAE Trans. 2014, 120, 437-448.

9. Lewandowski, T.A. Risk Assessment of Residential Heat Pump Systems Using 2L Flammable Refrigerants; AHRI Project 8004 Final Report; Air-Conditioning, Heating, and Refrigeration Institute: Arlington, VA, USA, 2012.

10. Boussouf, A.; Lecoustre, V.R.; Li, H.; By, R.; Sunderland, P.B. Ignition of R-32 and R-410A Refrigerant Mixtures with Lubricating Oil. In Proceedings of the Purdue Conference on Refrigeration and Air Conditioning, West Lafayette, IN, USA, 14-17 July 2014. 
11. Gandhi, P.; Hunter, G.; Haseman, R.; Rodgers, B. Benchmarking Risk by Whole Room Scale Leaks and Ignitions Testing of A2L Refrigerants; AHRTI Project 9007-01 Final Report; Air-Conditioning, Heating and Refrigeration Institute: Arlington, VA, USA, 2017.

12. Ballanco, J.; McCrudden, C.; Johnson, P. A2L Refrigerants: Safely Addressing Flammability Concerns. Engineered Systems Magazine, 27 November 2019.

13. ASHRAE, Inc. ANSI/ASHRAE Standard 34-2016, Designation and Safety Classification of Refrigerants; ASHRAE, Inc.: Atlanta, GA, USA, 2016.

14. Takizawa, K.; Tokuhashi, K.; Kondo, S. Flammability assessment of $\mathrm{CH}_{2}=\mathrm{CFCF}_{3}$ : Comparison with fluoroalkenes and fluoroalkanes. Hazard. Mater. 2009, 172, 1329-1338. [CrossRef]

15. Takizawa, K.; Igarashi, N.; Takagi, S.; Tokuhashi, K.; Kondo, S. Quenching distance measurement of highly to mildly flammable compounds. Fire. Saf. J. 2015, 71, 58-68. [CrossRef]

16. Kim, D.K.; Sunderland, P.B. Risk Investigation of Energy Produced by Potential Ignition Sources in Residential Application; AHRI Project 8017 Final Report; Air-Conditioning, Heating and Refrigeration Institute: Arlington, VA, USA, 2017.

17. Gradient Corp. Risk Assessment of Refrigeration Systems Using A2L Flammable Refrigerants; AHRI Project 8009 Final Report; Gradient Corp.: Arlington, VA, USA, 2015.

18. Minor, B.H.; Herrmann, D.; Gravell, R. Flammability characteristics of HFO-1234yf. Process Saf. Progr. 2010, $29,150-154$. [CrossRef]

19. Babushok, V.I.; Burgess, D.R., Jr.; Hegetschweiler, M.J.; Linteris, G.T. Flame propagation in the mixtures of $\mathrm{O}_{2} / \mathrm{N}_{2}$ oxidizer with fluorinated propene refrigerants $\left(\mathrm{CH}_{2} \mathrm{CFCF}_{3}, \mathrm{CHFCHCF}_{3}, \mathrm{CH}_{2} \mathrm{CHCF}_{3}\right)$. Combust. Sci. Technol. 2020. [CrossRef]

20. Spatz, M.; Minor, B. HFO-1234yf A Low GWP Refrigerant For MAC, Honeywell/DuPont Collaboration. In Proceedings of the International Refrigeration and Air Conditioning Conference, Saalfelden, Austria, 13-14 February 2008.

21. Honeywell. Solstice Propellant Flammability Assessment. 2016. Available online: http://www.crcind.com/crc/HFO-1234ze.pdf (accessed on 26 December 2020).

22. Honeywell. Honeywell Solstice yf Refrigerants Bulletin. 2012. Available online: https://www.honeywell-refrigerants.com/ europe/wp-content/uploads/2013/03/honeywell-solstice-yf-technical-bulletin.pdf (accessed on 26 December 2020).

23. Imamura, T.; Sugawa, O. Physical Hazard Evaluation of A2L-Class Refrigerants using Several Types of Conceivable Accident Scenarios. JSRAE 2013, 35-42. Available online: https:/ /www.jsrae.or.jp/info/2012progress_report_e.pdf (accessed on 26 December 2020).

24. Imamura, T.; Sugawa, O. Physical Hazard Evaluation of A2L Refrigerants Based on Several Conceivable Accident Scenarios. JSRAE 2014, 48-57. Available online: https:/ /www.jsrae.or.jp/committee/binensei/2014PR_e_ab.pdf (accessed on 26 December 2020).

25. Monforte, R.; Caretto, L. Safety Issues in the Application of a Flammable Refrigerant Gas in MAC Systems: The OEM Perspective; SAE International Paper 2009-07-0541; SAE International: Warrendale, PA, USA, 2009.

26. Imamura, T.; Kamiya, K.; Sugawa, O. Ignition hazard evaluation on A2L refrigerants in situations of service and maintenance. J. Loss Prev. Proc. Ind. 2015, 36, 553-561. [CrossRef]

27. Richard, R.G.; Spatz, M.W.; Motta, S.F.Y. Hot Surface Ignition with 2L Refrigerants; Honeywell Report; Honeywell Buffalo Research Laboratory: Buffalo, NY, USA, 2012.

28. Koban, M.; Minor, B.; Coughlan, P.; Gray, N. Hot Surface Ignition Testing of LOW GWP 2L Refrigerants. In Proceedings of the Purdue Conference on Refrigeration and Air Conditioning, West Lafayette, IN, USA, 11-14 July 2016.

29. Clodic, D.; Jabbour, T. Method of test for burning velocity measurement of flammable gases and results. HVACER Res. 2011, 17, 51-75.

30. Pagliaro, J.L.; Linteris, G.; Sunderland, P.B.; Baker, P.T. Combustion inhibition and enhancement of premixed methane-air flames by halon replacements. Combust. Flame 2015, 162, 41-49. [CrossRef]

31. Linteris, G.; Pagliaro, J.L.; Sunderland, P.B. Test Results Prepared for Honeywell: Igniter Material Effects in the Japanese High Pressure Gas Law Test; Technical Note (NIST TN)_1902; NIST: Gaithersburg, MD, USA, 2016.

32. JSRAE. Risk Assessment of Mildly Flammable Refrigerants: Final Report 2016; The Japan Society of Refrigerating and Air Conditioning Engineers: Tokyo, Japan, 2017; pp. 22-34.

33. Kataoka, O.; Yoshizawa, M.; Ohnishi, H.; Ishida, S. Flammability Evaluation of HFC-32 and HFC-32/134a Under Practical Operating Conditions. In Proceedings of the Purdue Conference on Refrigeration and Air Conditioning, West Lafayette, IN, USA, 23-26 July 1996.

34. Takahashi, A.; Urano, Y.; Tokuhashi, K.; Kondo, S. Effect of vessel size and shape on experimental flammability limits of gases. J. Hazard. Mater. 2003, 105, 27-37. [CrossRef]

35. Kul, I.; Gnann, D.L.; Beyerlein, A.L.; DesMarteau, D.D. Lower flammability limit of difluoromethane and percolation theory. Int. J. Thermophys. 2004, 25, 1085-1095. [CrossRef]

36. Kul, I.; Blaszkowski, C. Flammability studies of isomeric structures of ethane derivatives and percolation theory. Int. J. Thermophys. 2007, 28, 906-917. [CrossRef]

37. Feng, B.; Yang, Z.; Zhai, R. Climate change and refrigerants: Experimental study on the influence of the flame retardants on the flammability of R1234yf. Energy 2018, 143, 212-218. [CrossRef]

38. Gu, W.; Cheng, P.; Tang, M. Compilation and evaluation of gas phase diffusion coefficients of halogenated organic compounds. R. Soc. Open Sci. 2018, 5, 171936. [CrossRef] [PubMed]

39. Senecal, J.A. Flame extinguishing in the cup-burner by inert gases. Fire Saf. J. 2005, 40, 579-591. [CrossRef] 